\title{
ARTICLE \\ Inflammasome activation is required for human rhinovirus- induced airway inflammation in naive and allergen-sensitized mice
}

Mingyuan Han $^{1}$, J. Kelley Bentley ${ }^{1}$, Charu Rajput ${ }^{1}$, Jing Lei ${ }^{1}$, Tomoko Ishikawa ${ }^{1}$, Caitlin R. Jarman ${ }^{1}$, Julie Lee ${ }^{1}$, Adam M. Goldsmith ${ }^{1}$, William T. Jackson ${ }^{2}$, Mark J. Hoenerhoff ${ }^{3}$, Toby C. Lewis ${ }^{1}$ and Marc B. Hershenson ${ }^{1,4}$

Activation of the inflammasome is a key function of the innate immune response that regulates inflammation in response to microbial substances. Inflammasome activation by human rhinovirus (RV), a major cause of asthma exacerbations, has not been well studied. We examined whether RV induces inflammasome activation in vivo, molecular mechanisms underlying RV-stimulated inflammasome priming and activation, and the contribution of inflammasome activation to RV-induced airway inflammation and exacerbation. RV infection triggered lung mRNA and protein expression of pro-IL-1 $\beta$ and NLRP3, indicative of inflammasome priming, as well as cleavage of caspase- 1 and pro-IL-1 $\beta$, completing inflammasome activation. Immunofluorescence staining showed IL-1 $\beta$ in lung macrophages. Depletion with clodronate liposomes and adoptive transfer experiments showed macrophages to be required and sufficient for RV-induced inflammasome activation. TLR2 was required for RV-induced inflammasome priming in vivo. UV irradiation blocked inflammasome activation and RV genome was sufficient for inflammasome activation in primed cells. Naive and house dust mite-treated NLRP3-/- and IL-1 $\beta-/-$ mice, as well as IL-1 receptor antagonist-treated mice, showed attenuated airway inflammation and responsiveness following RV infection. We conclude that RV-induced inflammasome activation is required for maximal airway inflammation and hyperresponsiveness in naive and allergic mice. The inflammasome represents a molecular target for RV-induced asthma exacerbations.

Mucosal Immunology (2019) 12:958-968; https://doi.org/10.1038/s41385-019-0172-2

\section{INTRODUCTION}

Activation of the inflammasome is a key function of the innate immune response that regulates inflammation and pyroptosis, a lytic form of cell death, in response to detected stimuli. ${ }^{1}$ Inflammasomes consists of three main components: a pattern recognition receptor; an adaptor protein that consists of a pyrin domain and a caspase recruitment domain; and the cysteine protease caspase- 1 as the effector. At least five pattern recognition receptors have been shown to assemble inflammasomes. Nucleotide-binding oligomerization domain, leucine-rich repeat and pyrin domain containing 3 (NLRP3) detects a diverse series of agonists including pathogens (bacteria, fungi, viruses) and sterile environmental stimuli, such as asbestos and silica. ${ }^{2,3} \mathrm{~A}$ two-step model has been suggested for NLRP3 inflammasome activation. ${ }^{4}$ The first step, priming by extracellular inflammatory stimuli, induces NLRP3 and pro-interleukin (IL)-1 $\beta$ expression. The second step, which may be triggered by an array of cellular mechanisms, including release of oxidized mitochondrial DNA, reactive oxygen, mitochondrial dysfunction, lysosomal rupture, and intracellular calcium and potassium efflux, activates caspase-1- mediated proteolytic cleavage of pro-inflammatory IL-1 family cytokines into their bioactive forms, IL-1 $\beta$ and IL-18.
Evidence exists for inflammasome activation in asthma. IL-1 $\beta$ was increased in sputum and bronchoalveolar lavage (BAL) fluid of patients with neutrophilic ${ }^{5}$ and $T$ helper type 2 (Th2)/Th17predominant asthma. ${ }^{6}$ Sputum macrophages from patients with neutrophilic asthma also showed elevated mRNA expression of NLRP3, caspase- 1 , and IL-1 $\beta$, as well as increased NLRP3 and caspase1 protein abundance, ${ }^{7}$ evidence of NLRP3 inflammasome activation. Gene signatures of NLRP1, NLRP3, and NLRC4 were increased in sputum cells of nonsmoking patients with severe neutrophilic or eosinophilic asthma. ${ }^{8}$ In contrast, compared to healthy volunteers, expression of inflammasome genes was decreased in samples of sputum inflammatory cells from patients with allergic rhinitis or asthma. ${ }^{9}$ Finally, IL-1 $\beta$ promotes airway hyperresponsiveness in rodents sensitized to ovalbumin, a model allergen.10,11

Human rhinovirus (RV), a member of the family Picornaviridae, genus Enterovirus, carries a single-stranded positive RNA genome, about $7.5 \mathrm{~kb}$ in size. Four structural proteins, VP1, VP2, VP3, and the myristoylated VP4, ${ }^{12}$ form the icosahedral capsid. First identified as the most common cause of upper respiratory tract infections, advances in molecular methods of viral detection have linked RV infections to exacerbations of chronic pulmonary disease, in particular asthma and chronic obstructive pulmonary

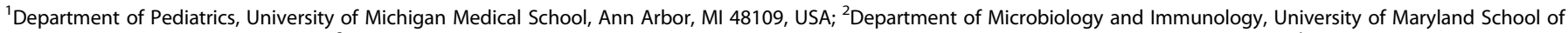

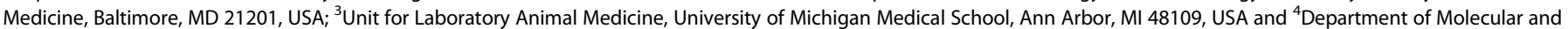
Integrative Physiology, University of Michigan Medical School, Ann Arbor, MI 48109, USA

Correspondence: Marc B. Hershenson (mhershen@umich.edu)
}

Received: 16 January 2019 Revised: 9 April 2019 Accepted: 29 April 2019

Published online: 15 May 2019 
disease. ${ }^{13,14} \mathrm{RV}$ is the most common cause of asthma exacerbation in children ${ }^{15,16}$ and adults. ${ }^{13,17}$

In cultured bronchial epithelial cells, RV infection induces NLRP3 inflammasome activation ${ }^{18,19}$ and IL-1 $\beta$ secretion. ${ }^{20}$ Experimental human RV infection increases nasal IL-1 $\beta .^{21-23}$ However, the association between RV-induced inflammasome activation and airway inflammation has not been established in vivo.

In this study, we examined the effects of RV infection on inflammasome activation in naive mice as well as those with allergic airway disease. We found that RV induces inflammasome activation in vivo and that inflammasome activation plays an essential role in RV-induced airway inflammation and hyperresponsiveness. We also identified primary roles for Toll-like receptor 2 (TLR2) activation and viral genome in inflammasome priming and activation, respectively.

\section{RESULTS}

$\mathrm{RV}$ infection activates the inflammasome in vivo

Previous studies have shown NLRP3 inflammasome activation in RV-infected bronchial epithelial cells. ${ }^{18,19}$ We employed in vivo model to determine the role of RV infection in inflammasome activation. We collected lungs from RV-infected mice and measured IL-1 $\beta$ and IL-18 mRNA and protein. IL-1 $\beta$ mRNA and protein expression, but not IL-18, was increased in RV-infected mice at early time points of infection (Fig. $1 \mathrm{a}, \mathrm{b}$ ). In addition, mRNA expression of the pro-inflammatory cytokines $\mathrm{CxCl1}, \| / 6$ and $T N F a$ and the IL-1 receptor antagonist $/ / 1 \mathrm{rn}$ was increased (Fig. 1a). RV increased protein expression of NLRP3 and pro-IL-1 $\beta$ (Fig. 1c, d), indicative of the RV-induced priming step. RV also triggered cleavage of pro-IL-1 $\beta$ and caspase- 1 and subsequent production of IL-1 $\beta$ and caspase- 1 p12, demonstrating inflammasome activation in the lungs of RV-infected mice.

To determine the cellular source of inflammasome activation, we examined airway IL-1 $\beta$ deposition by immunofluorescence. Infection with RV increased airway IL-1 $\beta$ expression, with the strongest signal found in subepithelial $\mathrm{F} 4 / 80^{+}$cells, indicative of airway macrophages (Fig. 1e). There was less IL-1 $\beta$ staining in the airway epithelium.

Next, we delivered clodronate- or phosphate-buffered saline (PBS)containing liposomes to mice intratracheally to deplete macrophages as previously described. ${ }^{24}$ Twenty-four hours later, mice were inoculated with sham or RV. Clodronate treatment significantly reduced whole-lung IL-1 $\beta$ mRNA in RV-infected mice (Fig. 1f). RVinduced protein expression of NLRP3 and pro-IL-1 $\beta$ as well as the production of mature IL-1 $\beta$ and caspase- 1 p12 were also reduced in clodronate-treated mice (Fig. 1g), confirming the macrophage to be the major cellular source of inflammasome activation.

We tested the sufficiency of macrophages for inflammasome activation by transferring bone marrow-derived macrophages from wild-type and IL-1 $\beta-/-$ mice to the airways of sham-treated and RV-infected IL-1 $\beta-/$ - mice. IL-1 $\beta-/$ - mice receiving macrophages from IL-1 $\beta-/-$ mice showed no inflammasome activation following RV infection. However, IL-1 $\beta-/-$ mice receiving macrophages from wild-type mice and infected with RV showed a significant increase in NLRP3, pro-IL-1 $\beta$, IL-1 $\beta$, and caspase-1 p12 (Fig. 1h).

Finally, to test inflammasome activation by a major group RV strain, THP-1 human monocytic cells were infected with RV-16, a major group virus, and RV-1A and RV-1B, two minor group viruses. Each infection showed cleaved caspase-1 and IL-1 $\beta$ (Fig. 1i). Secreted IL-1 $\beta$ was also detected in the culture supernatant of virus-infected cells, demonstrating inflammasome activation by major and minor RV strains.

NLRP3 is required for RV-induced inflammasome activation We examined RV-induced lung mRNA expression of different pattern recognition receptors involved in inflammasome formation. RV induced N/rp1, NIrp3, and NIrc5 mRNA expression but not Aim2, NIrC3 or NIrC4 (Fig. 2a). Immunoblots and immunofluorescence staining showed increased lung NLRP3 protein expression in RV-infected mice (Figs. 1c and 2b). Similar to IL-1 $\beta$, large subepithelial cell F4/80-positive cells were highly positive for NLRP3 expression (Fig. 2b). Again, there was less NLRP3 staining in the airway epithelium.

We examined the requirement of NLRP3 for inflammasome activation using NLRP3-/- mice. RV-infected NLRP3-/- mice showed significantly decreased caspase- 1 p12 and IL-1 $\beta$ levels, suggesting that NLRP3 is required for the RV inflammasome activation step (Fig. 2c, d). NLRP3-/- also slightly reduced $/ 11 b$ mRNA (Fig. 2e) and pro-IL-1 $\beta$ protein expression (Fig. $2 c, d$ ), consistent with previous reports of an IL-1 $\beta$ autocrine loop. ${ }^{25,26}$

TLR2 is required and sufficient for the priming step of RV-induced inflammasome

TLR2 is required for RV-induced cytokine responses in vivo. ${ }^{27}$ We employed TLR2-/- mice to determine the role of TLR2 in RVinduced inflammasome activation. Compared to wild-type mice, RVinduced $1 / 16$, il1rn, Nlrp3, Nlrc5, and Tnf mRNA expression was blocked in TLR2-/- mice (Fig. 3a). TLR2-/- mice also showed a reduction in RV-induced lung IL-1 $\beta$ protein level compared to wild type (Fig. 3b). Consistent with decreased mRNA expression, TLR2-/- mice showed a reduction in RV-induced protein abundance of pro-IL1b and NLRP3, demonstrating a block in inflammasome priming (Fig. 3c, d). Immunoblots also showed reduced caspase- 1 p12 and mature IL- $1 \beta$ in TLR2 $-/-$ mice. We also infected bone marrow-derived macrophages isolated from wild-type and TLR2-/- mice with RV. Macrophages from TLR2-/- mice showed similar results as whole lung, with attenuated RV-induced expression of pro-IL-1 $\beta$, NLRP3, mature IL-1 $\beta$, and caspase-1 p12 (Fig. 3e). However, lipopolysaccharide (LPS), a TLR4 ligand, increased pro-IL-1 $\beta$ and NLRP3 in both wild-type and TLR2-/- macrophages. Together, our results suggest that the RV-TLR2 interaction is essential for the priming step of inflammasome activation, which in turn is necessary for inflammasome activation.

We have recently found that the RV-TLR2 interaction is mediated by the myristoylated viral capsid protein VP4. ${ }^{28}$ We treated bone marrow-derived macrophages from wild-type mice with synthetic MyrVP4. Immunoblots showed increased protein abundance of pro-IL-1 $\beta$ (Fig. 3f). However, the bioactive product IL-1 $\beta$ was not present, in contrast to RV-treated cells. In addition, MyrVP4-induced pro-IL-1 $\beta$ expression was decreased in bone marrow-derived macrophages from TLR2 $-/-$ mice. Thus TLR2 is not only required but also sufficient for inflammasome priming.

Ultraviolet (UV) irradiation attenuates inflammasome activation in RV-infected mice

Recognition of viral RNA triggers activation of the NLRP3 inflammasome, which in return mediates innate immune responses against RNA viruses. ${ }^{29,30}$ We examined the effect of UV irradiation (which damages the viral genome and prevents its replication) on RV-induced inflammasome priming and activation by immunoblot. C57BL/6 mice treated with UV-irradiated RV-1B showed unchanged pro-IL-1 $\beta$ and NLRP3 expression levels, indicating an intact priming step (Fig. 4a, b). However, UV irradiation of RV-1B attenuated cleavage of caspase- 1 p12 and IL-1 $\beta$, suggesting the essential role of viral RNA in inflammasome activation.

Transfection of single-stranded RNA is sufficient for inflammasome activation

RV induced inflammasome activation in mouse bone marrowderived macrophages that do not support viral replication. ${ }^{31}$ It is therefore plausible that single-stranded viral genomic RNA, rather than double-stranded RNA (dsRNA) formed during viral replication, is sufficient for inflammasome activation. To test this, human THP-1 cells were primed with LPS for $6 \mathrm{~h}$ and then subjected to transient transfection with control single-strand RNA or in vitrotranscribed RV-1A genomic RNA. LPS-primed THP-1 cells showed 

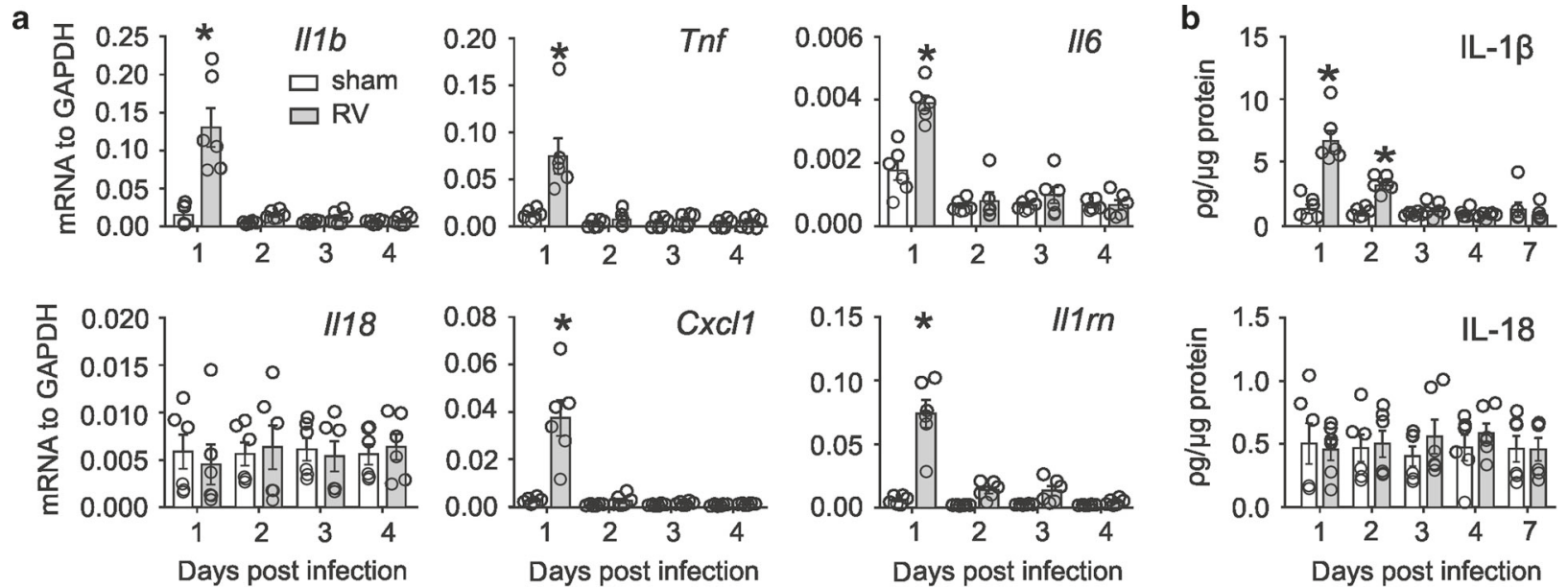

c Sham RV

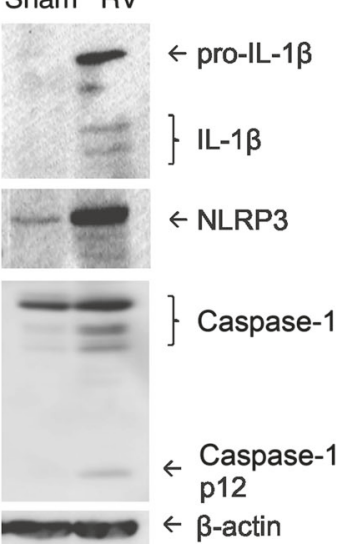

d

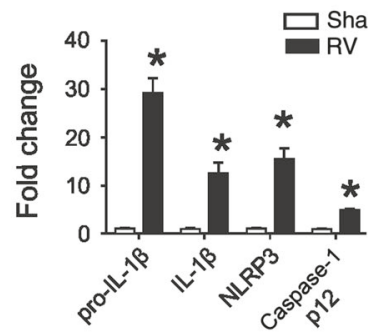

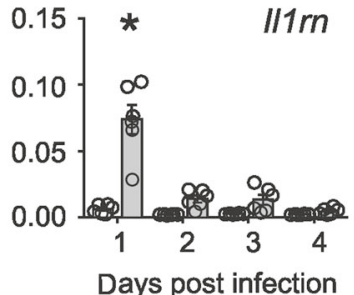

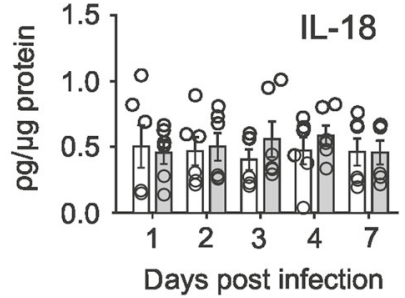

e
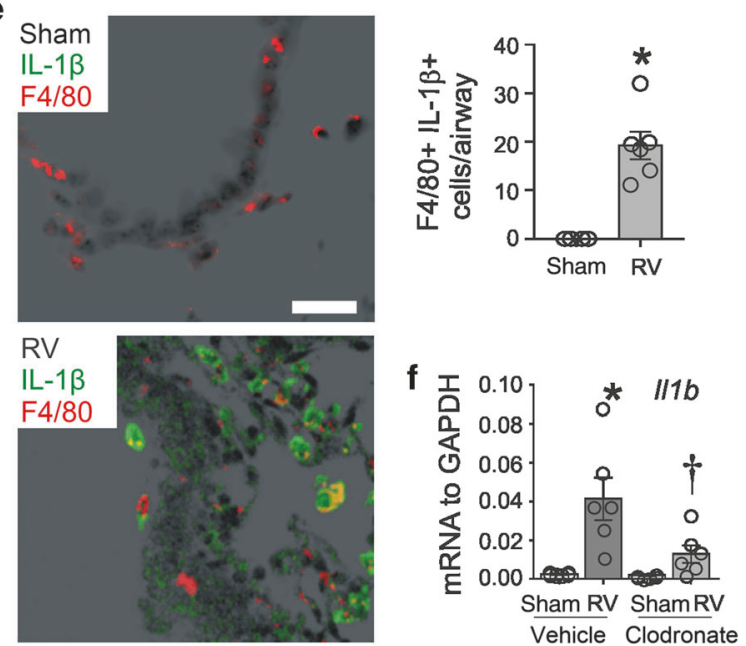

g $\frac{\text { Vehicle Clodronate }}{\text { Sham RV Sham RV }}$

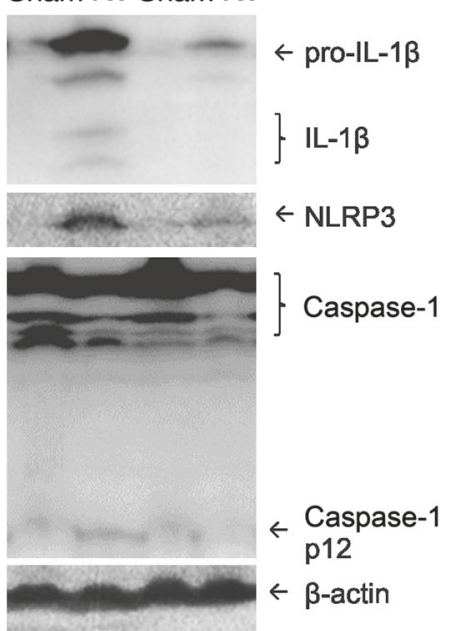

h

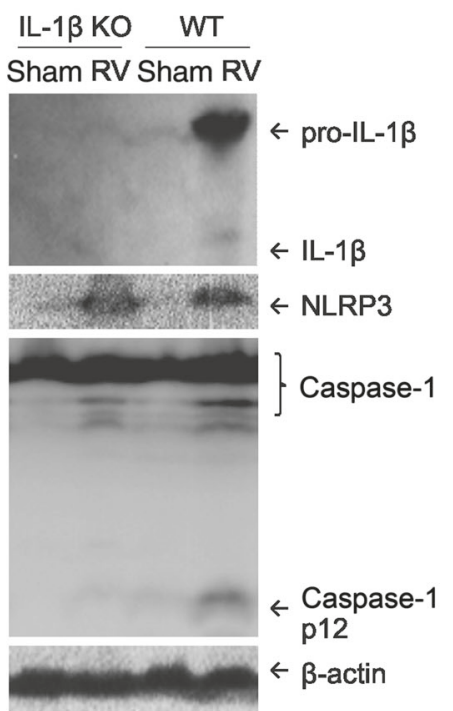

i

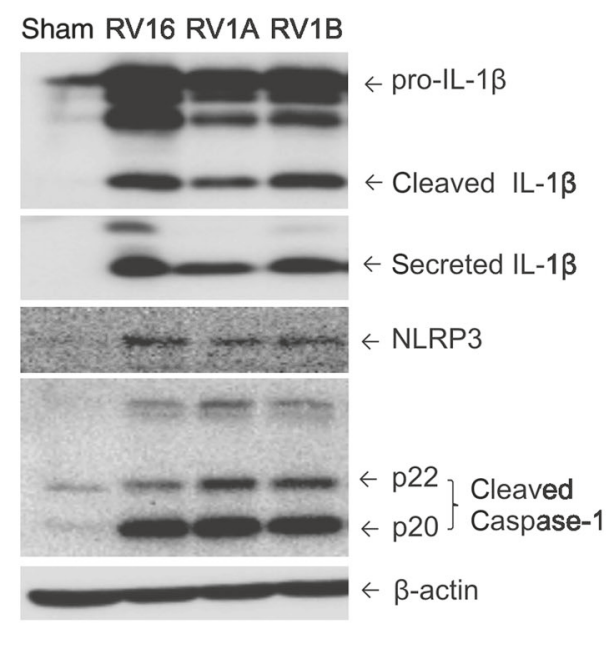

increased expression of pro-IL-1 $\beta$ and NLRP3 but limited mature IL-1 $\beta$ and caspase-1 p20 and p22 (Fig. 4c). Transfection of LPStreated cells with control single-stranded and RV-1A genomic RNA each induced increased expression of mature IL-1 $\beta$ and caspase- 1 p20 and p22, suggesting that, in primed cells, single-stranded RNA is sufficient for inflammasome activation
NLRP3 and IL-1 $\beta$ knockouts attenuate RV-induced airway inflammation in naive mice

We examined differences in RV response between wild-type, NLRP3 $-/-$, and IL-1 $\beta-/-$ mice. Lungs of wild-type animals revealed peribronchial inflammatory and intraluminal infiltrates (Fig. 5a). In contrast, RV-infected NLRP3-/- and IL-1 $\beta-/-$ mice 
Fig. 1 Rhinovirus (RV) activates inflammasome in vivo. C57BL/6 mice were inoculated with sham or RV. Lung mRNA (a) and protein (b) expression were measured $1,2,3,4$, or 7 days later. $\left(N=6\right.$ from two different experiments, mean $\pm S E M,{ }^{*}$ different from sham, $p<0.05$, twoway analysis of variance (ANOVA) with Tukey's multiple comparisons test.) c One day after infection, whole lungs were homogenized and subjected to western blot. Anti-mouse-IL-1 $\beta$ recognizes pro-IL-1 $\beta$ and its bioactive form interleukin (IL)- $1 \beta$. Anti-mouse-caspase- 1 detects both caspase-1 and its cleaved form, caspase-1 p12. d Group mean relative expression levels were normalized to $\beta$-actin. ( $N=12$ from six different experiments, mean $\pm \mathrm{SEM}$, *different from sham, $p<0.05$, two-way ANOVA.) e Lungs were stained for IL-1 $\beta$ (green), F4/80 (red), and nuclei (DAPI, black; bar, $50 \mu \mathrm{m}$ ). Average number of $\mathrm{F} 4 / 80^{+} \mathrm{IL}-1 \beta^{+}$cells per airway $\left(N=6\right.$ from two different experiments, mean $\pm \mathrm{SEM}$, ${ }^{*}$ different from sham, $p<0.05$, unpaired $t$ test.) $\mathbf{f}, \mathbf{g}$ Clodronate- or phosphate-buffered saline-containing liposomes were delivered to mice intratracheally $24 \mathrm{~h}$ before sham or RV infection. One day after infection, lungs were harvested for mRNA and western blot $(N=6$ from one experiment, mean \pm SEM, * different from sham, $p<0.05$, two-way ANOVA). $\mathbf{h}$ Bone marrow cells from either wild-type or IL-1 $\beta-/-$ mice were cultured in L929 media for 7 days. Macrophages were transferred to IL-1 $\beta-/-$ mice intratracheally at $10^{6}$ cells per mouse $24 \mathrm{~h}$ before RV infection. One day after infection, lungs were harvested for western blot analysis. (Image is representative of $N=3$ from one experiment.) i Human THP-1 (10 ${ }^{6}$ cells) were infected with sham, RV-16, RV-1A, or RV-1B at a multiplicity of infection of 1 for $24 \mathrm{~h}$. Both cell lysate and supernatant were collected for immunoblot assay. Anti-human-capase-1 recognizes two forms of cleaved caspase-1, p22 and p20. Anti-human-IL-1 $\beta$ recognizes pro-IL-1 $\beta$ and IL-1 $\beta$. (Image is representative of $N=3$ from two experiments.) For clarity, individual data points are not shown for d

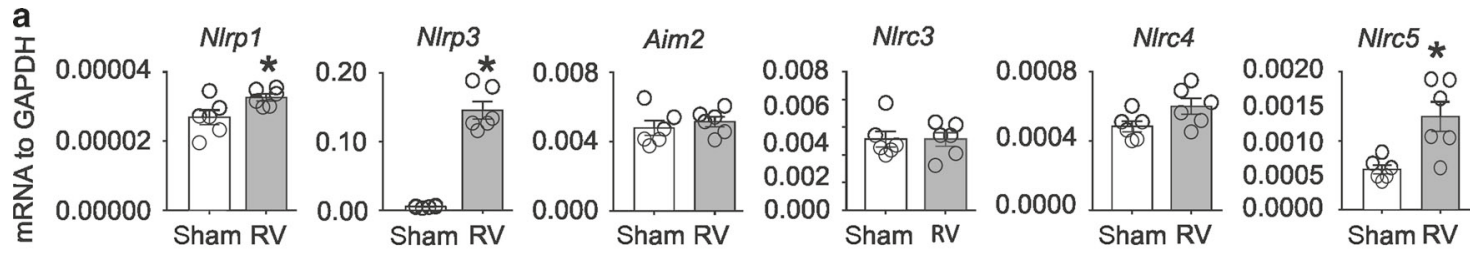

b

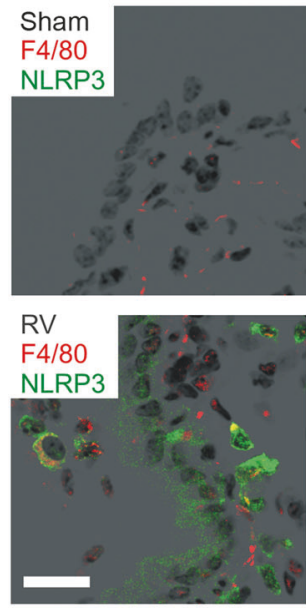

C

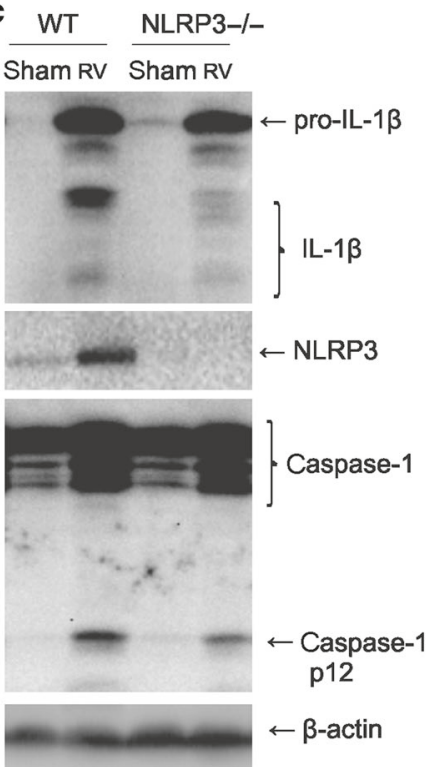

d
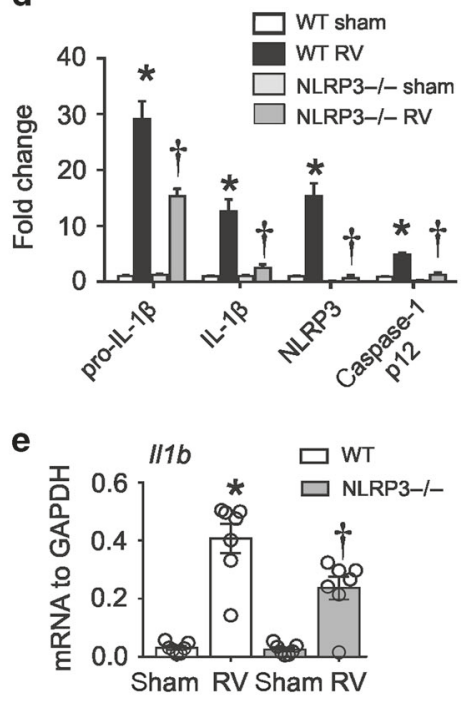

Fig. 2 Nucleotide-binding oligomerization domain, leucine- rich repeat and pyrin domain containing 3 (NLRP3) is required for rhinovirus (RV)triggered inflammasome. Wild-type C57BL/6 (WT) or NLRP3-/- mice were inoculated with sham or RV for $24 \mathrm{~h}$. a Lung mRNAs were measured by quantitative PCR ( $N=6$ from two different experiments, mean \pm SEM, *different from sham, $p<0.05$, unpaired $t$ test). $\mathbf{b}$ Lungs were stained for NLRP3 (green), F4/80 (red), and nuclei (DAPI, black; bar, $50 \mu \mathrm{m})$. Average number of F4/80 ${ }^{+} \mathrm{NLRP3}^{+}$cells per airway $(N=6$ from one experiment, mean \pm SEM, ${ }^{*}$ different from sham, $p<0.05$, unpaired $t$ test.) $\mathbf{c}$, d Whole lungs collected from C57BL/6 and NLRP3-/mice were homogenized within lysis buffer and subjected to western blot. Group mean expression levels relative to $\beta$-actin are also shown. $\left(N=6\right.$ from three different experiments, mean $\pm S E M,{ }^{*}$ different from sham, ${ }^{\dagger}$ different from wild type, $p<0.05$, two-way analysis of variance (ANOVA)) e Effect of NLRP3 $-/$ - on $I L 1 b$ mRNA ( $N=7$ from two different experiments, mean $\pm S E M,{ }^{*}$ different from WT sham, ${ }^{\dagger}$ different from WT RV, $p<0.05$, two-way ANOVA with Tukey's multiple comparisons test). For clarity, individual data points are not shown for d

showed minimal inflammation. BAL cell counts showed decreased numbers of total cells and neutrophils in RV-infected NLRP3-/and IL-1 $\beta-/-$ mice (Fig. 6d). Following RV infection, Cxcl1, Cxcl10, Tnf, and $/ 117$ mRNA expression were increased significantly $24 \mathrm{~h}$ postinfection of wild-type $\mathrm{C} 57 \mathrm{BL} / 6$ mice but reduced in NLRP3 $-/-$ and IL-1 $\beta-/-$ mice (Fig. $5 b$ ). In addition, NLRP3-/and IL-1 $\beta-/-$ mice showed decreased airway cholinergic responsiveness following RV infection (Fig. 5c).

We have previously shown that inoculation of mice with RV-1B is associated with modest viral replication. ${ }^{32,33}$ Compared to wild- type C57BL/6 mice, NLRP3-/- and IL1b-/- mice showed small $(1 / 2$ log) but statistically significant increases in viral copy number (Fig. 5d).

Hematoxylin and eosin (H\&E) staining showed that treatment with anti-IL-1 $\beta$ blocked peribronchial inflammatory and intraluminal infiltrates (Fig. 5e). Expression of mRNAs encoding IL-1 $\beta$, IL$1 \mathrm{RN}$, tumor necrosis factor (TNF)- $a$, NLRP3, C-X-C chemokine motif ligand 1 (CXCL-1) and CXCL-2 was decreased (Fig. 5f). Taken together, these results show that IL-1 $\beta$ plays a key role in the development of lung inflammation in RV-infected mice. 

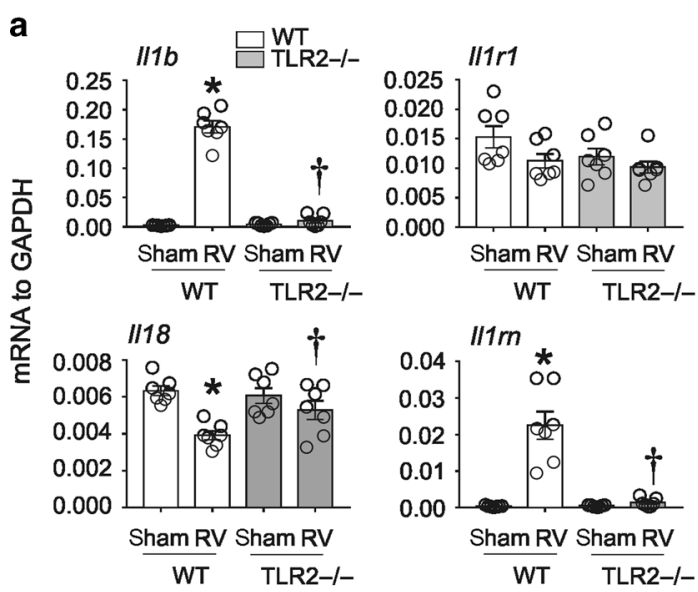

C
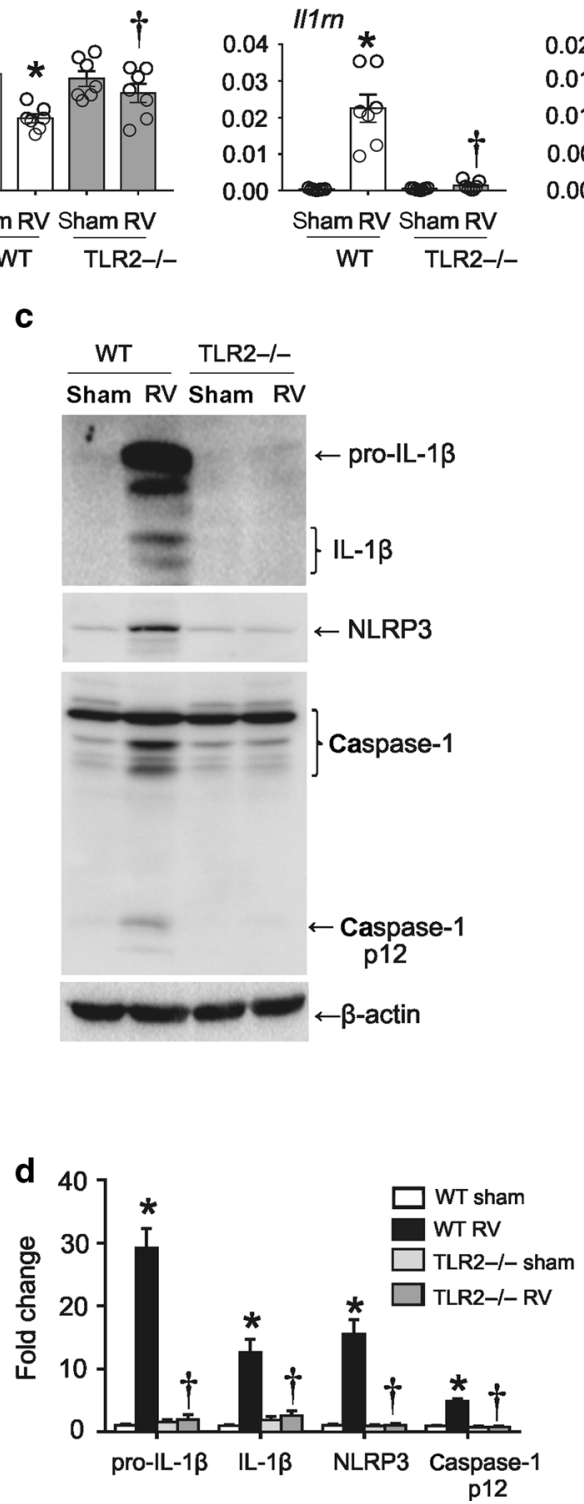
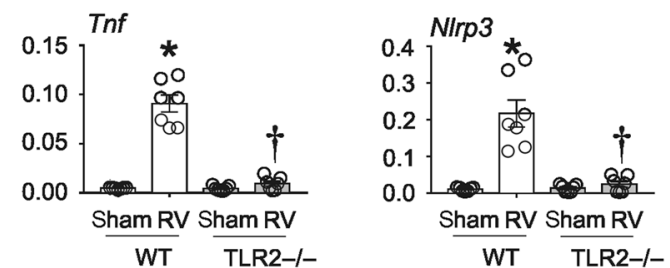

b
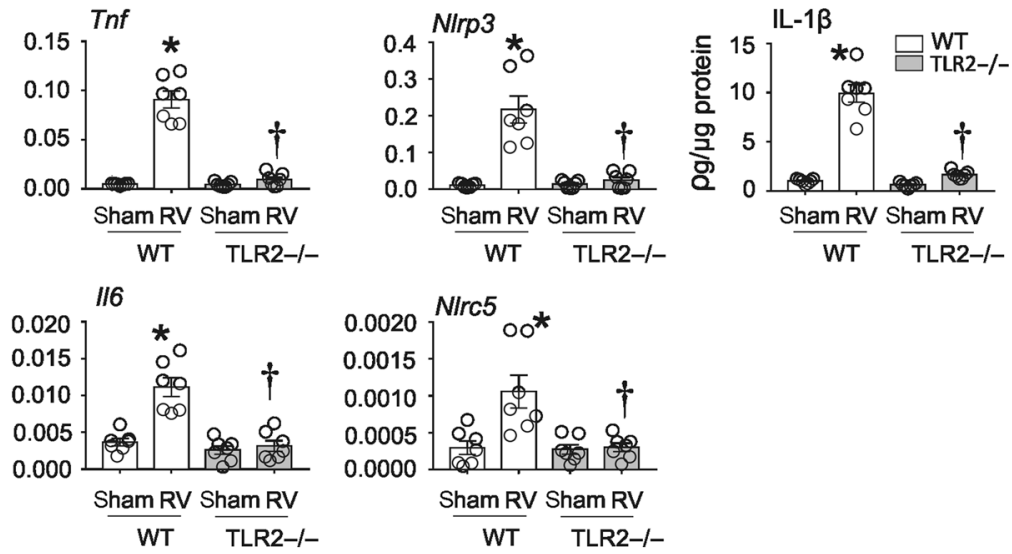

e
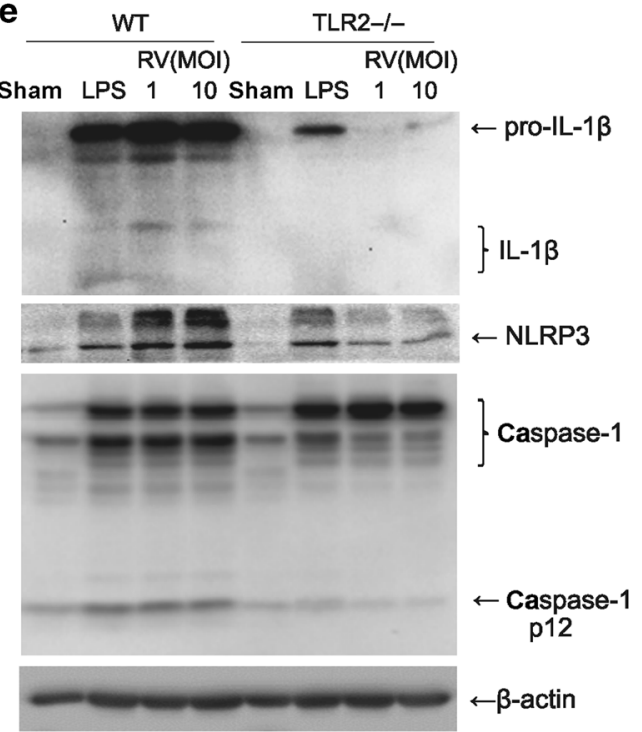

f

WT

TLR2-I-

Sham RV LPS Sham VP4 Sham RV LPS Sham VP4 PBS PBS DMSO DMSO DMSO PBS PBS DMSO DMSODMSO

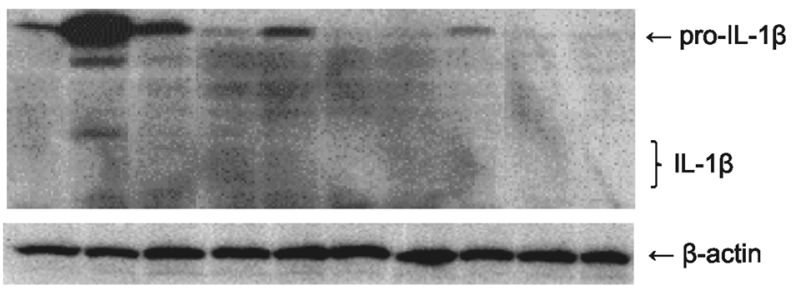

Fig. 3 Rhinovirus (RV)-induced inflammasome activation is Toll-like receptor 2 (TLR2) dependent. Wild-type C57BL/6 (WT) or TLR2-/- mice were inoculated with sham or RV for $24 \mathrm{~h}$. Lung mRNA (a), protein (b), and inflammasome activation (c, d) were assessed. $(N=6-7$ from two different experiments, mean \pm SEM, * different from WT sham, ${ }^{\dagger}$ different from WT RV, $p<0.05$, two-way analysis of variance) e Bone marrowderived macrophages from C57BL/6 (WT) or TLR2-/- mice were infected with sham or RV at a multiplicity of infection of 1 or 10 for $24 \mathrm{~h}$. Selected cells were primed with LPS $(100 \mathrm{ng} / \mathrm{ml})$ for $6 \mathrm{~h}$. (Image is representative of two experiments.) f Bone marrow-derived macrophages from C57BL/6 (WT) or TLR2-/- mice were treated with recombinant MyrVP4 $(500 \mathrm{ng} / \mathrm{ml})$ for $24 \mathrm{~h}$. (Image is representative of two experiments.) For clarity, individual data points are not shown for d

Reduction of type 2 inflammation and airway eosinophils in RVinfected house dust mite (HDM)-sensitized and HDM-challenged mice

We examined whether NLRP3 and IL-1 $\beta$ play roles in RV-mediated exacerbation of allergic airway disease. First, we examined the effect of allergen treatment on RV-induced lung inflammasome activation. We employed a clinically relevant mouse model designed to recapitulate RV-induced asthma exacerbation, as described previously. ${ }^{34}$ Wild-type C57BL/6 mice were sensitized with HDM and challenged with HDM 10 and 11 days after sensitization. Mice were infected with RV 1 day after the last challenge. HDM treatment induced modest pro-IL-1 $\beta$ synthesis but no mature IL-1 $\beta$ synthesis (Fig. $6 a, b)$ ). RV infection increased both pro-IL-1 $\beta$ and mature IL-1 $\beta$ synthesis in HDM-treated mice at 
a Sham RV UV-RV

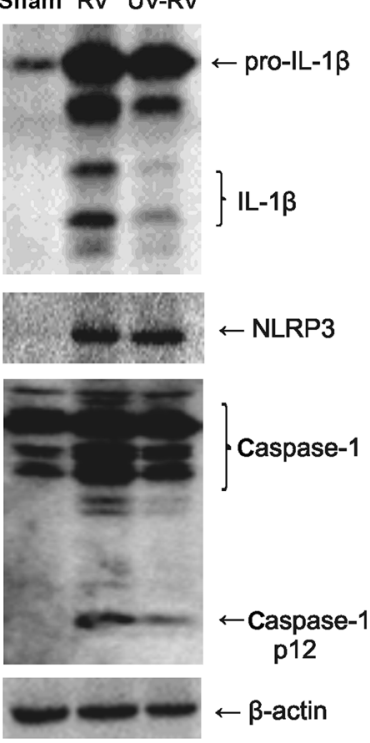

C

$$
\begin{array}{ccccccl}
- & + & + & + & + & + & \text { LPS } \\
- & - & + & + & + & + & \text { Lipofectamine } \\
- & - & - & \text { Ctrl } & \text { RV } & \text { RV } & \text { RNA } \\
& & & 2 \mu g & 2 \mu g & 4 \mu g &
\end{array}
$$

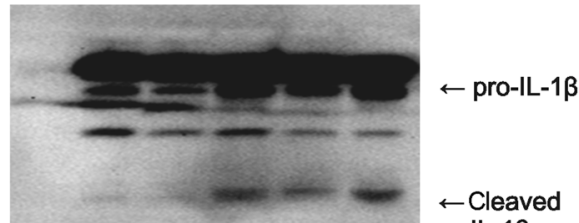

IL-1 $\beta$
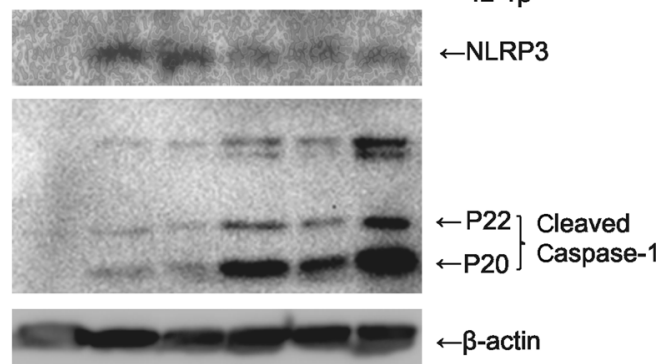

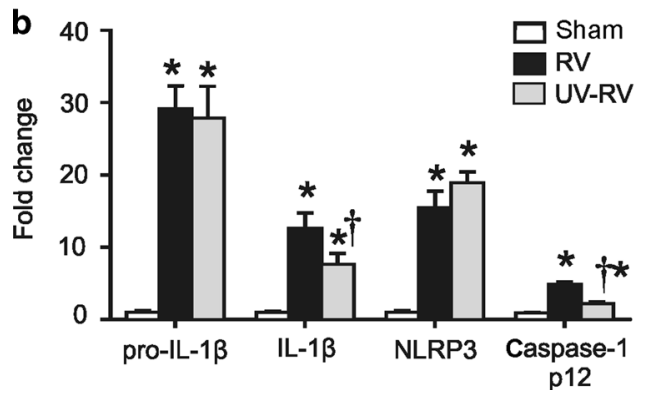

Fig. 4 Ultraviolet (UV) irradiation impairs rhinovirus (RV)-induced inflammasome activation. a Wild-type C57BL/6 mice were infected with sham, RV, or UV-RV for $24 \mathrm{~h}$. b Group mean relative expression levels were normalized to $\beta$-actin. ( $N=6$ from three different experiments, mean \pm SEM, * different from sham, $p<0.05{ }^{+}{ }^{\dagger}$ different from RV, two-way analysis of variance) c Human THP-1 cells were preincubated with lipopolysaccharide (LPS; $1 \mu \mathrm{g} / \mathrm{ml}$ ) for $6 \mathrm{~h}$. The LPS-primed cells were then transfected with control or viral genomic single-stranded RNA for $20 \mathrm{~h}$. Whole-cell lysate was assessed for inflammasome activation by immunoblot. (Image is representative of two experiments.) For clarity, individual data points are not shown for $\mathbf{b}$

day 1 postinfection, evidence of inflammasome priming and activation. However, mRNA expression of IL-1 $\beta$ and NLRP3 and abundance of mature IL-1 $\beta$ and $\mathrm{p} 12$ caspase 1 were reduced compared to PBS-treated RV-infected mice, suggesting that allergen treatment partially attenuates inflammasome priming and activation (Fig. 6a-c).

Sham-infected HDM-sensitized and HDM-challenged mice exhibited signs of allergic airway inflammation compared to sham-infected naive controls, including increased BAL total cells, eosinophils, and lymphocytes (Fig. 6d, e). In addition, HDMsensitized and HDM-challenged mice inoculated with RV displayed exacerbated airway inflammation compared HDM-treated mice inoculated with sham, including increased total BAL cells; neutrophils; eosinophils; lymphocytes (Fig. 6d); airway responsiveness (Fig. 6e); and mRNA expression of $114,115,1113$, and $\mathrm{CCl} 24$ (Fig. 6g).

Next, we examined airway inflammation in HDM-sensitized and HDM-challenged, RV-infected, wild-type, NLRP3-/-, and IL-1 $\beta-/-$ mice. Compared to wild type, HDM-sensitized and HDM-challenged NLRP3-/- and IL-1 $\beta-/-$ mice showed significantly reduced RV-induced total cells, neutrophils, lymphocytes, and eosinophils, as well as reduced cytokine mRNA expression (Fig. 6d, g). HDM-treated and RV-infected NLRP3-/and IL1 $\beta-/-$ mice showed reduced airway responsiveness compared to RV-infected HDM-treated wild-type mice (Fig. 6f).
We also examined the effects of a recombinant IL- 1 receptor antagonist on RV-induced inflammation in HDM-treated mice. Recombinant IL-1RA was given after HDM treatment, $1 \mathrm{~h}$ before and $24 \mathrm{~h}$ after RV infection. IL-1RA significantly attenuated RVinduced eosinophilic inflammation and type 2 cytokine mRNA expression in allergen-treated mice (Fig. $6 \mathrm{~h}, \mathrm{i})$.

\section{DISCUSSION}

RV is an important cause of asthma exacerbation. However, the precise mechanisms underlying RV-induced asthma exacerbation are uncertain. Activation of the inflammasome is a key function of the innate immune response that regulates inflammation in response to microbial substances, including viral infections. Influenza is a well-known stimulus of inflammasome activation. ${ }^{29,35-37}$ However, inflammasome activation by RV, perhaps the most common human infection, has not been well studied. While RV has been shown to induce NLRP3 inflammasome activation ${ }^{18,19}$ and IL-1 $\beta$ secretion ${ }^{19,20}$ in cultured bronchial epithelial cells, little is known about RV-induced inflammasome activation in vivo or its contribution to airway inflammation and exacerbation of allergic airway disease. To address this in a mechanistic manner, we infected C57BL/6 mice with RV-1B, a minor group strain that replicates in mouse and human cells. ${ }^{38} \mathrm{RV}$ infection triggered inflammasome priming and activation. Lung 
a

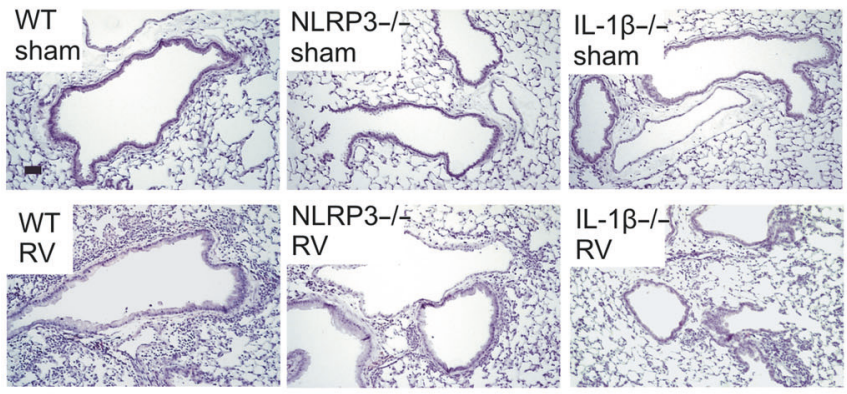

C

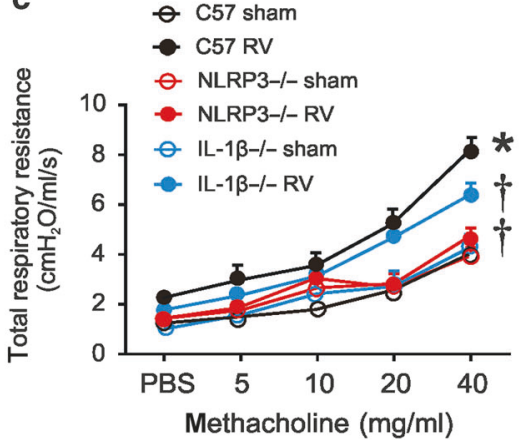

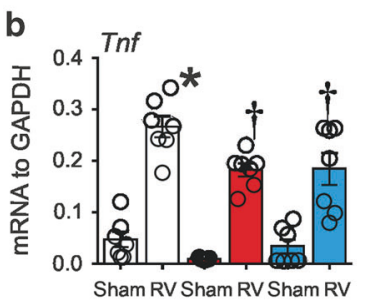
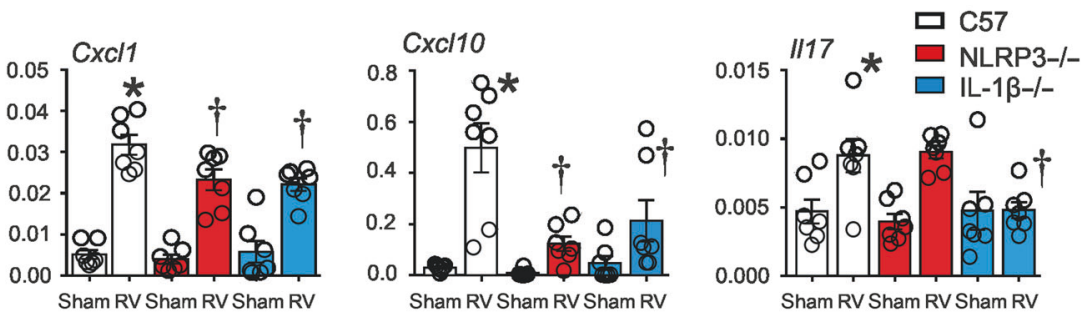

d

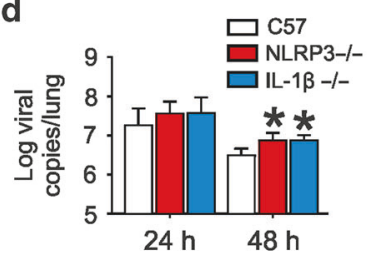

\section{e}
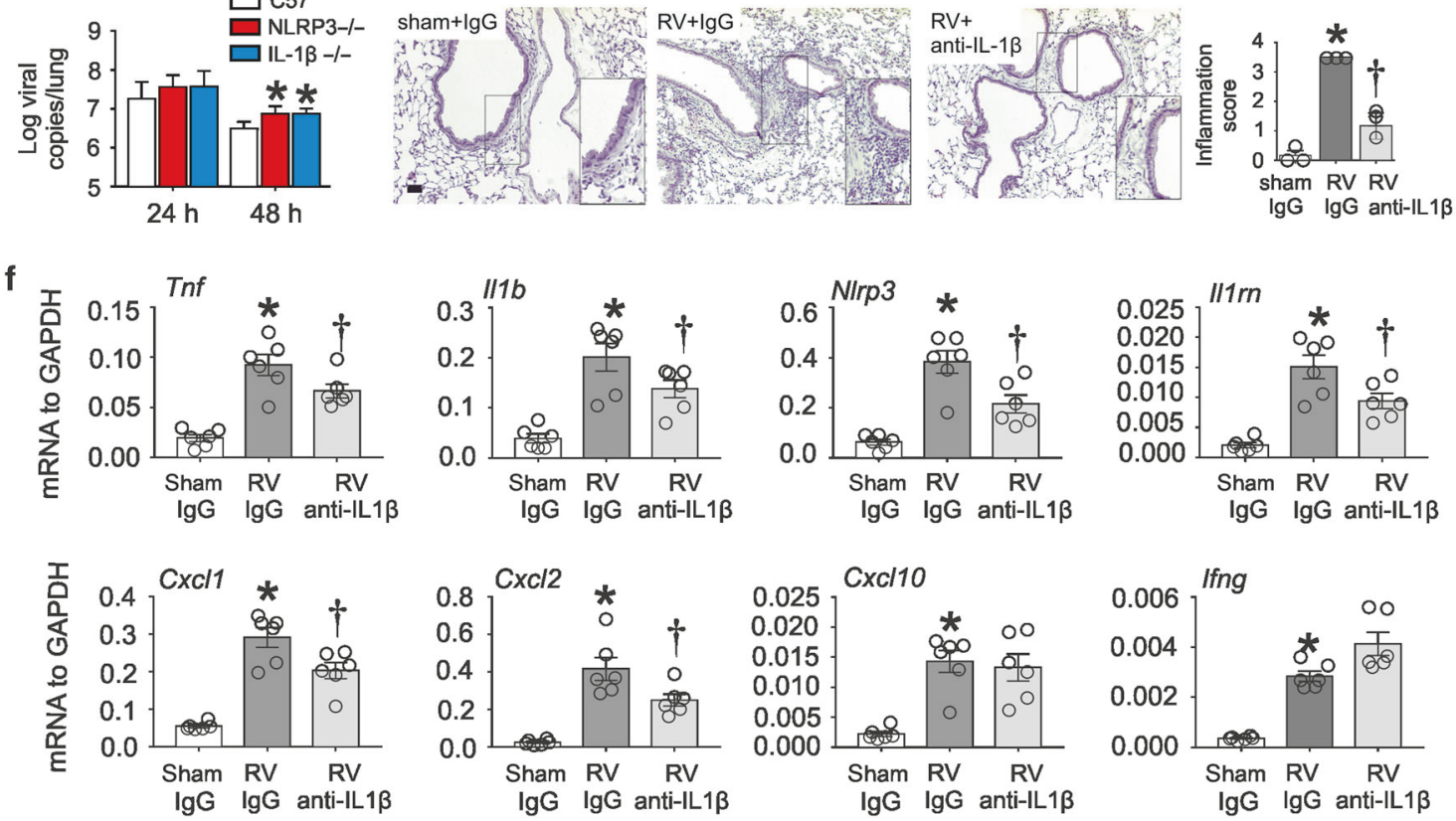

Fig. 5 Inhibition of rhinovirus (RV)-induced airway inflammation and hyperresponsiveness in NLRP3-/-, IL-1 $\beta-/-$, and anti-IL-1 $\beta$ treated mice. a C57BL/6 (wild-type (WT)), NLRP3 $-/-$, or IL-1 $\beta-/-$ mice were intranasally infected with sham or RV. Lung sections were prepared 2 days after infection. $\mathbf{b}$ Transcript levels of pro-inflammatory cytokines were assessed 1 day postinfection by quantitative PCR and results were expressed as fold change over GAPDH $\left(N=7\right.$ from two different experiments, mean \pm SEM, ${ }^{*}$ different from WT sham, ${ }^{+}$different from WT $\mathrm{RV}, p<0.05$, two-way analysis of variance (ANOVA)). c Airway hyperresponsiveness was measured in sham- or RV-treated WT, NLRP3-/-, and IL-1 $\beta-/-$ mice 2 days after treatment. ( $N=4$ from 2 different experiments, mean \pm SEM, ${ }^{*}$ different from WT RV, ${ }^{\dagger}$ different from WT RV, $p<0.05$, two-way ANOVA with Tukey's multiple comparisons test.) $\mathbf{d}$ RV-positive-strand RNA was assessed 24-48 $\mathrm{h}$ after infection and presented as viral copy numbers in total lung. ( $N=7$ from two different experiments, mean $\pm S E M$, *different from WT RV, $p<0.05$, two-way ANOVA with Tukey's

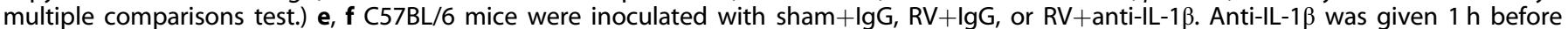
infection to selected RV-treated mice. After $24 \mathrm{~h}$, lungs were harvested for histology (e, bar is $50 \mu \mathrm{m})$, inflammation score $(N=3$ from 1 experiment), and mRNA expression ( $N=6$ from 2 different experiments, mean $\pm \mathrm{SEM},{ }^{*}$ different from sham $+\mathrm{lgG},{ }^{\dagger} \mathrm{different}$ from $\mathrm{RV}+\mathrm{lgG}, p<$ 0.05 , one-way ANOVA with Tukey's multiple comparisons test.) For clarity, individual data points are not shown for $\mathbf{c}$, $\mathbf{d}$

macrophages were a major cellular source of IL-1 $\beta$. TLR2 was required and myristoylated VP4, a TLR2 ligand, were sufficient for inflammasome priming. In contrast, UV irradiation blocked RVinduced inflammasome activation and single-stranded RV genome was sufficient for this process, indicating a key role for the RV genome in inflammasome activation. Naive NLRP3- and IL-1 $\beta$ deficient mice showed attenuated RV-induced airway inflammation (fewer BAL cells and reduced lung cytokine levels), despite a slightly increased viral load. RV infection of HDMsensitized and HDM-challenged mice showed additive or synergistic type 2 inflammatory responses, which were reduced in NLRP3- and IL-1 $\beta$-deficient mice, as well as in wild-type mice treated with $\mathrm{LL}-1$ receptor antagonist. Together, these data show for the first time that inflammasome activation is required for 

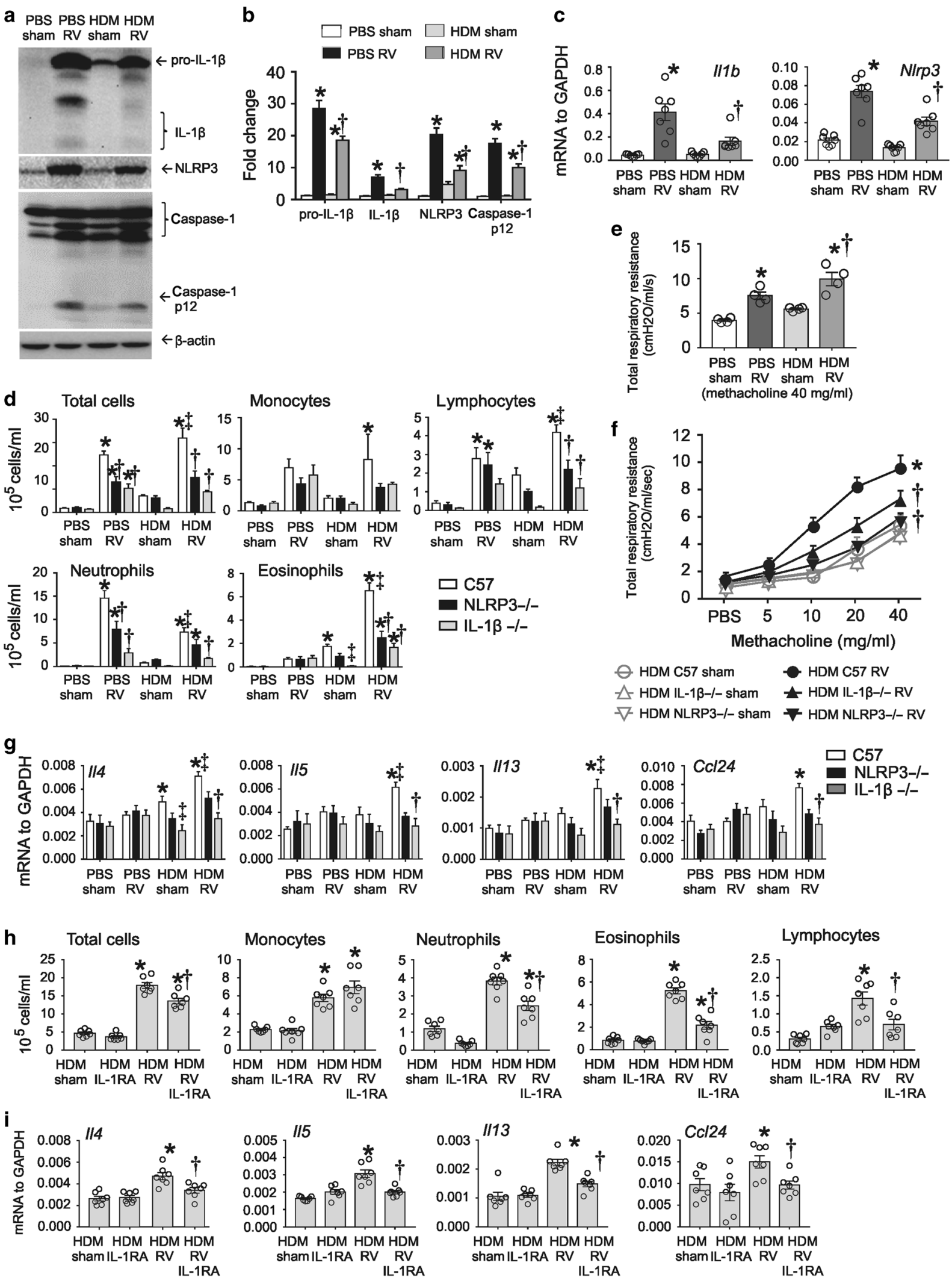

RV-induced airway inflammation in naive and allergensensitized mice.

Our data are consistent with previous work showing reduced lung inflammation in influenza-infected mice lacking the NLRP3

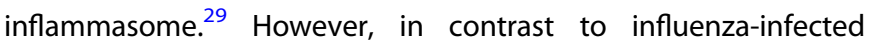
NLRP3-deficient mice with increased mortality, RV-infected NLRP3-/- mice showed reduced airway responsiveness. Airway inflammation and responsiveness were reduced in NLRP3- and 
Fig. 6 Inflammasome inhibition attenuates rhinovirus (RV)-induced allergic airway inflammation and type-2 immune response in house dust mite (HDM)-sensitized mice. Whole lungs collected from phosphate-buffered saline (PBS)- or HDM-treated wild-type (WT) mice 1 day post-RV infection were subjected to western blot $(\mathbf{a}, \mathbf{b})$ and quantitative PCR analysis $(\mathbf{c})$. $\left(N=7\right.$ from 2 different experiments, mean \pm SEM, ${ }^{*}$ different from WT sham, ${ }^{\dagger}$ different from WT RV, $p<0.05$, two-way analysis of variance (ANOVA) with Tukey's multiple comparisons test.) $\mathbf{d}$ Differential immune cell counts in bronchoalveolar lavage (BAL) of PBS- or HDM-sensitized and HDM-challenged, sham-, or RV-treated WT, NLRP3-/-, and IL-1 $\beta-/-$ mice $\left(10^{5}\right.$ cells $\left./ \mathrm{ml}\right) 2$ days after treatment $\left(N=7\right.$ from 2 different experiments, mean \pm SEM, ${ }^{*}$ different from WT sham, ${ }^{+}$different from WT PBS RV or WT HDM RV, ${ }^{\ddagger}$ different from WT HDM sham, $p<0.05$, two-way ANOVA with Tukey's multiple comparisons test). e, $\mathbf{f}$ Airway responsiveness was measured in PBS- or HDM-sensitized and HDM-challenged, sham-, or RV-treated WT, NLRP3-/-, and IL-1 $\beta-/-$ mice 2 days after treatment. ( $N=4$ from two different experiments, mean $\pm \mathrm{SEM}$, ${ }^{*}$ different from WT sham, ${ }^{\dagger}$ different from WT RV, $p<0.05$, two-way ANOVA). $\mathbf{g}$ mRNA levels of type 2 cytokines in the mice lungs. $(N=7$ from two different experiments, mean $\pm S E M$, *different from WT sham, ${ }^{\dagger}$ different from WT PBS RV or WT HDM RV, ${ }^{\ddagger}$ different from WT HDM sham, $p<0.05$ two-way ANOVA with Tukey's multiple comparisons test). $\mathbf{h}$, i Recombinant IL-1RA (10 mg/kg body weight) was given after HDM treatment, $1 \mathrm{~h}$ before and $24 \mathrm{~h}$ after RV infection. BAL cell counts (h) and lung mRNA levels of type 2 cytokines (i) were measured 2 days post-RV infection. ( $N=7$ from 2 different experiments, mean $\pm S E M$, *different from HDM-sham, ${ }^{\dagger}$ different from HDM RV, $p<0.05$, one-way ANOVA). For clarity, individual data points are not shown for $\mathbf{b}, \mathbf{f}, \mathbf{g}$

IL-1 $\beta$-deficient mice despite the fact that viral copy number was significantly higher $48 \mathrm{~h}$ after infection. Thus, in the context of a non-lethal lung infection, inflammasome activation was deleterious to the host, leading to an asthma exacerbation-like phenotype. While the amount of viral replication in our model is limited, these data are consistent with the notion that disproportionate inflammation, rather than viral-induced cellular damage, is the cause of RV-induced asthma exacerbation.

Previous studies have examined the role of the inflammasome products IL-1 $\beta$ and IL-18 in RV infection but in a limited fashion. RV infection has been shown to induce IL-1 $\beta$ secretion in cultured bronchial epithelial cells. ${ }^{1920}$ IL-1 $\beta$ potentiated RV-1B-induced CXCL-8 production in cultured BEAS-2B airway epithelial cells. ${ }^{39}$ Administration of an $\mathrm{IL}-1$ receptor antagonist decreases RVinduced IL-6 and IL-8 production in primary bronchial epithelial cells. ${ }^{40}$ Experimental human RV infection increases IL-1 $\beta^{21-23}$ and $\mathrm{IL}-18^{41}$ in nasal washings. However, we did not observe an increase in IL-18 mRNA in RV-infected mice nor did we find an IL18 signal in children with natural RV infections.

While in vitro studies of RV-induced inflammasome activation have focused on airway epithelial cells, ${ }^{18,19}$ we found that subepithelial macrophages produce $\mathrm{IL}-1 \beta$ in response to $\mathrm{RV}$ infection in vivo. Macrophages were required and sufficient for RVinduced lung inflammasome activation. These data are consistent with previous work showing that caspase- 1 inflammasome activation in the hematopoietic, but not stromal, compartment was required to induce protective antiviral immunity in influenzainfected mice. ${ }^{37}$ These data provide further support to the concept that airway macrophages are the main source of inflammatory cytokines following RV infection, in contrast to airway epithelial cells, ${ }^{24}$ which support viral replication.

We found that TLR2 was required for RV-induced mRNA expression of pro-IL-1 $\beta$ and NLRP3 in C57BL/6 mice and cultured macrophages. MyrVP4 induced mRNA expression of pro-IL-1 $\beta$ and NLRP3 in cultured macrophages but not the bioactive products IL-1 $\beta$ and caspase- 1 p12. MyrVP4-induced priming was blocked in TLR2-/- cells. In contrast, inflammasome priming by LPS, a TLR4 ligand, was not blocked in TLR2-/- cells. These data show that MyrVP4/TLR2 signaling is sufficient for inflammasome priming but not activation.

In mice, intact viral RNA was required for cleavage of caspase-1 and production of mature IL-1 $\beta$. The requirement of dsRNA for influenza-induced NLRP3 inflammasome activation has been shown previously. ${ }^{29,36,37}$ However, in the present study, RV infection induced inflammasome activation in mouse bone marrow-derived macrophages, which do not support viral replication, ${ }^{31}$ and transient transfection of single-stranded viral RNA was sufficient for inflammasome activation in LPS-primed cells. These data provide a mechanism by which macrophages might rapidly initiate inflammasome activation in response to viral infection, without the need for viral replication.

Employing NLRP3 $-/-$ and IL-1 $\beta-/-$ mice as well as recombinant IL-1 $\beta$ receptor antagonist, we found that inflammasome activation was required for RV-induced airway eosinophilic inflammation and type 2 cytokine expression in HDM-sensitized and HDM-challenged mice. Previous studies have examined inflammasome activation in mice with allergic airway disease, in combination with an infectious agent or other stimuli. Ovalbuminsensitized mice infected with Chlamydia muridarum develop NLRP3 inflammasome activation and steroid-resistant allergic airway disease. ${ }^{42} \mathrm{HDM}$-sensitized $\mathrm{IL}-1 \beta-/-$ mice treated with dsRNA (to simulate a viral infection) demonstrate attenuated neutrophilic inflammation and Th2 cytokine expression, whereas caspase-1-/- mice show reduced eosinophilic inflammation and Th2 cytokine expression. ${ }^{43,44}$ However, in contrast to previous studies, we employed a physiologic pathogen that is a common cause of asthma exacerbations. To underline this point, we have found that, in bone marrow-derived macrophages, RV-induced TNF- $a$ expression is TLR2/MyD88 dependent, in contrast to dsRNAinduced cytokine expression, which is dependent on TLR3. ${ }^{31}$ Thus dsRNA may not be an accurate model of RV infection. Further, unlike previous studies, we also examined the effect of inflammasome blockade on airway responsiveness and viral load. Inflammasome activation was required for airway hyperresponsiveness and IL-1 $\beta$ blockade increased viral load.

Finally, while inflammasome activation was required for maximum type 2 inflammation after RV infection in allergic mice, we found that HDM in actual fact attenuated RV-induced inflammasome activation. This finding is consistent with previous data showing that inflammasome activation may be reduced in some asthmatics. ${ }^{9}$ Thus the contribution of inflammasome activation to airway inflammation may depend on the type and severity of asthma, combined with the burden of respiratory viral infection. It is also conceivable that the level of inflammasome activation, in combination with other cytokines, regulates the nature of the subsequent inflammatory response, with "highdose" IL-1 $\beta$ contributing to expansion of type 1 innate lymphoid cells and interferon- $\gamma$ production and "low-dose" IL-1 $\beta$ contributing to expansion of type 2 innate lymphoid cells and IL-13 production. ${ }^{45,46}$

We conclude that RV infection induces TLR2-dependent inflammasome activation in naive mice and also activates the inflammasome in mice with allergic airway disease. These data provide a new mechanism by which RV could contribute to the development of asthma exacerbations and provide molecular targets of treatment.

\section{MATERIAL AND METHODS}

\section{RV infection of mice}

Experiments were approved by the Institutional Animal Care and Use Committee. RV-1B (ATCC, Manassas, VA) was partially purified by ultrafiltration using a 100-kD filter and titered by plaque assay. ${ }^{32}$ In some experiments. RV was inactivated by UV light. C57BL/6, TLR2-/- (Jackson Laboratories, Bar Harbor, ME), 
NLRP3 $-/-$, or IL-1 $\beta-/-$ mice, ${ }^{47}$ generally in a 1:1 male-to-female ratio, were inoculated intranasally under Forane anesthesia with $50 \mu \mathrm{l} \mathrm{RV}-1 \mathrm{~B}\left(5 \times 10^{6}\right.$ plaque-forming unit/mouse $)$ or sham HeLa cell lysate. Mice were sensitized and challenged by intranasal exposure to HDM extract (Greer Laboratories, Lenoir, NC) and infected with $50 \mu \mathrm{l}$ RV-1B 1 day after exposure. Selected mice were treated intraperitoneally with $30 \mu \mathrm{g}$ anti-IL-1 $\beta$ (R\&D Systems, Minneapolis, MN) or $10 \mathrm{mg} / \mathrm{kg}$ IL-1 receptor antagonist (PeproTech, Rocky Hill, NJ).

Mouse model of RV-induced exacerbation of allergic airway inflammation

Using a previously published protocol, ${ }^{34}$ anesthetized mice were sensitized by intranasal exposure to HDM extract $(100 \mu \mathrm{g}$ in $50 \mu \mathrm{l}$ PBS, Greer Laboratories, Lenoir, NC). Controls received $50 \mu$ PBS. Ten days later, mice were dosed intranasally with $10 \mu \mathrm{g}$ of HDM in $50 \mu \mathrm{l}$ of PBS on 2 consecutive days. One day after the last challenge, allergic and control mice were inoculated intranasally with $50 \mu \mathrm{l}$ RV-1B as described above. Selected mice were treated intraperitoneally with $10 \mathrm{mg} / \mathrm{kg}$ human recombinant IL-1 receptor antagonist (PeproTech, Rocky Hill, NJ) after HDM treatment, $1 \mathrm{~h}$ before and $24 \mathrm{~h}$ after RV infection. This antagonist is effective against mouse IL-1 receptor.

Assessment of airway responsiveness

Airway responsiveness was assessed by measuring changes in total respiratory system resistance after increasing doses of nebulized methacholine administered through an endotracheal tube. ${ }^{39}$ Mechanical ventilation was conducted and total respiratory system resistance measured using a Buxco FinePointe operating system (Buxco, Wilmington, NC).

Analysis of lung inflammation

Differential counts of BAL inflammatory cells were performed as described previously. ${ }^{48}$ Lung sections were stained with H\&E or Alexa Fluor-conjugated anti-mouse NLRP3 (Cell Signaling, Danvers, MA), anti-IL-1 $\beta$ (R\&D), anti-CD68, and/or anti-F4/80 (Biolegend, San Diego, CA). Pathological categories of perivascular/ peribronchiolar and alveolar inflammation were examined and scored on a scale of $0-4(0=$ no lesion, $1=$ minimal: focal to multifocal infiltrates barely exceeding background; $2=$ mild: focal to multifocal infiltrates easily identified but of limited severity; $3=$ moderate: multifocal to locally extensive infiltrates prominent but significant potential for increased severity; $4=$ severe: locally extensive to diffuse infiltrates involving large portions of the section). In addition, the number of $\mathrm{F} 4 / 80^{+} \mathrm{IL}-1 \beta^{+}$and $\mathrm{F} 4 /$ $80^{+} \mathrm{NLRP}^{+}$cells in and around airways was quantified by the $\mathrm{NIH}$ ImageJ software (Bethesda, MD). Four airways from one section per mouse were randomly selected for analysis.

After Trizol solubilization, purified RNA was processed for firststrand $c D N A$ and quantitative PCR ( $q P C R$ ) using reverse transcriptase and SYBR green qPCR reagents (ThermoFisher Scientific, Waltham, MA). To quantify virus particles, qPCR for positive-strand viral RNA was conducted using RV-specific primers and probes. ${ }^{49}$ Primers used are described in Supplemental Table S1. IL-1 $\beta$ and IL18 were measured by enzyme-linked immunosorbent assay ( $R \& D)$.

\section{Cell culture}

Mouse bone marrow monocytes were isolated and cultured in L929 medium for 7 days as described. ${ }^{31}$ Cells were infected with RV-1B at a multiplicity of infection (MOI) of 1 or 10 , treated with $500 \mathrm{ng} / \mathrm{ml}$ synthetic myristoylated RV capsid protein VP4 (MyrVP4, GenScript, Piscataway, NJ), or primed with $100 \mathrm{ng} / \mathrm{ml}$ Escherichia coli 0111:B4 LPS (Sigma-Aldrich, St. Louis). THP-1 human monocytic cells (ATCC) were infected with $1 \mathrm{MOI}$ RV-1B, RV-16, and RV-1A (ATCC) or transfected with full-length RV-1A genome or control single-stranded RNA using Lipofectamine (Thermo Fisher).
In vitro RNA synthesis and transfection

The RV infectious clone pMJ3-HRV-1A was described previously. ${ }^{50}$ Full-length viral RNA was generated using the MEGAScript T7 Transcription Kit (Thermo Fisher Scientific) and used to transfect human THP-1 cells using Lipofectamine (Thermo Fisher Scientific). A control single-stranded RNA was in vitro synthesized using the plasmid pTRI-Xef provided in the MEGAScript T7 Transcription Kit. pTRI-Xef contains $1.85 \mathrm{~kb}$ of Xenopus elongation factor $1 \mathrm{a}$ gene.

Inflammasome priming and activation

Lysates were subjected to western blot assay using anti-mouse IL$1 \beta$ (R\&D), caspase-1 (Abcam, Cambridge, MA), and NLRP3 (Cell Signaling) or anti-human IL-1 $\beta$ (R\&D) or caspase-1 (Abcam).

Macrophage depletion

Depletion of alveolar macrophages was accomplished by intratracheal instillation of liposomes containing clodronate (dichloromethylenediphosphonic acid, disodium salt, Millipore Sigma, Burlington, MA), as previously described. ${ }^{24}$ PBS-containing liposomes were used for control experiments. Liposomes were kept at $4{ }^{\circ} \mathrm{C}$ under $\mathrm{N}_{2}$ until use. Depletion was performed $24 \mathrm{~h}$ before sham or RV infection by introducing $50 \mu$ l of clodronate- or PBScontaining liposomes intratracheally under Forane anesthesia.

Adoptive transfer of macrophages to the airways

Mouse macrophages were isolated from either wild type or IL-1 $\beta$ mice and cultured in L929 medium. Macrophages were transferred to mice intratracheally at $10^{6}$ cells per mouse $24 \mathrm{~h}$ before RV infection. $^{27}$

Data analysis

Data are represented as mean \pm standard error. Statistical significance was assessed by unpaired $t$ test or one-way or twoway analysis of variance, as appropriate. Group differences were pinpointed by a Tukey's multiple comparison test.

\section{ACKNOWLEDGEMENTS}

The authors thank Dr. Gabriel Núñez (University of Michigan, Ann Arbor, MI) for his gift of NLRP3-/- and IL1 $3-/-$ mice. This work was supported by an NIH grant HL134369 (to M.B.H)

\section{AUTHOR CONTRIBUTIONS}

Study design: M.H., W.T.J., M.J.H., T.C.L., and M.B.H.; data collection: M.H., J.K.B., C.R., J. L., T.I., J.L., C.R.J., J.L., and A.M.G.; analysis: M.H., M.J.H., and M.B.H.; manuscript drafting and editing-M.H. and M.B.H.; manuscript approval-all authors.

\section{ADDITIONAL INFORMATION}

The online version of this article (https://doi.org/10.1038/s41385-019-0172-2) contains supplementary material, which is available to authorized users.

Competing interests: The authors declare no competing interests.

Publisher's note: Springer Nature remains neutral with regard to jurisdictional claims in published maps and institutional affiliations.

\section{REFERENCES}

1. Guo, H., Callaway, J. B. \& Ting, J. P. Inflammasomes: mechanism of action, role in disease, and therapeutics. Nat. Med. 21, 677-687 (2015).

2. Franchi, L., Eigenbrod, T. \& Núñez, G. Cutting Edge: TNF-a mediates sensitization to ATP and silica via the NLRP3 inflammasome in the absence of microbial stimulation. J. Immunol. 183, 792-796 (2009).

3. Franchi, L. et al. Cytosolic double-stranded RNA activates the NLRP3 inflammasome via MAVS-induced membrane permeabilization and $\mathrm{K}+$ efflux. J. Immunol. 193, 4214-4222 (2014).

4. He, Y., Hara, H. \& Núñez, G. Mechanism and regulation of NLRP3 inflammasome activation. Trends Biochem. Sci. 41, 1012-1021 (2016). 
5. Hastie, A. T. et al. Analyses of asthma severity phenotypes and inflammatory proteins in subjects stratified by sputum granulocytes. J. Allergy Clin. Immunol. 125, 1028-1036 (2010).

6. Liu, W. et al. Mechanism of Th2/Th17-predominant and neutrophilic Th2/Th17low subtypes of asthma. J. Allergy Clin. Immunol. 139, 1548-1558 (2017).

7. Simpson, J. L. et al. Elevated expression of the NLRP3 inflammasome in neutrophilic asthma. Eur. Respir. J. 43, 1067-1076 (2014).

8. Rossios, C. et al. Sputum transcriptomics reveal upregulation of IL-1 receptor family members in patients with severe asthma. J. Allergy Clin. Immunol. 141, 560-570 (2018).

9. Brickey, W. J. et al. Sputum inflammatory cells from patients with allergic rhinitis and asthma have decreased inflammasome gene expression. J. Allergy Clin. Immunol. 128, 900-903 (2011).

10. Tsukagoshi, H., Sakamoto, T., Xu, W., Barnes, P. J. \& Chung, K. F. Effect of interleukin-1 $\beta$ on airway hyperresponsiveness and inflammation in sensitized and nonsensitized Brown-Norway rats. J. Allergy Clin. Immunol. 93, 464-469 (1994).

11. Kobayashi, T., lijima, K., Checkel, J. L. \& Kita, H. IL-1 family cytokines drive Th2 and Th17 cells to innocuous airborne antigens. Am. J. Respir. Cell Mol. Biol. 49, 989-998 (2013).

12. Oliveira, M. A. et al. The structure of human rhinovirus-16. Structure 1, 51-68 (1993).

13. Corne, J. M. et al. Frequency, severity, and duration of rhinovirus infections in asthmatic and non-asthmatic individuals: a longitudinal cohort study. Lancet 359, 831-834 (2002).

14. Greenberg, S. B., Allen, M., Wilson, J. \& Atmar, R. L. Respiratory viral infections in adults with and without chronic obstructive pulmonary disease. Am. J. Respir. Crit. Care Med. 162, 167-173 (2000).

15. Johnston, S. L. et al. Community study of role of viral infections in exacerbations of asthma in 9-11 year old children. BMJ 310, 1225-1229 (1995).

16. Heymann, P. W. et al. Viral infections in relation to age, atopy, and season of admission among children hospitalized for wheezing. J. Allergy Clin. Immunol. 114, 239-247 (2004)

17. Nicholson, K. G., Kent, J. \& Ireland, D. C. Respiratory viruses and exacerbations of asthma in adults. BMJ 307, 982-986 (1993).

18. Triantafilou, K., Kar, S., van Kuppeveld, F. J. \& Triantafilou, M. Rhinovirus-induced calcium flux triggers NLRP3 and NLRC5 activation in bronchial cells. Am. J. Respir. Cell Mol. Biol. 49, 923-934 (2013).

19. Shi, L., Manthei, D. M., Guadarrama, A. G., Lenertz, L. Y. \& Denlinger, L. C. Rhinovirus-induced IL-1 $\beta$ release from bronchial epithelial cells is independent of functional P2X7. Am. J. Respir. Cell Mol. Biol. 47, 363-371 (2012).

20. Terajima, M. et al. Rhinovirus infection of primary cultures of human tracheal epithelium: role of ICAM-1 and IL-1 beta. Am. J. Physiol. 273, 749-759 (1997).

21. Proud, D. et al. Increased levels of interleukin-1 are detected in nasal secretions of volunteers during experimental rhinovirus colds. J. Infect. Dis. 169, 1007-1013 (1994).

22. Yoon, H. J., Zhu, Z., Gwaltney, J. M. \& Elias, J. A. Rhinovirus regulation of IL-1 receptor antagonist in vivo and in vitro: a potential mechanism of symptom resolution. J. Immunol. 162, 7461-7469 (1999).

23. Kluijver, J. D. et al. Interleukin-1 $\beta$ and interleukin-1RA levels in nasal lavages during experimental rhinovirus infection in asthmatic and non-asthmatic subjects. Clin. Exp. Allergy 33, 1415-1418 (2003).

24. Nagarkar, D. R. et al. Rhinovirus infection of allergen-sensitized and-challenged mice induces eotaxin release from functionally polarized macrophages. J. Immunol. 185, 2525-2535 (2010).

25. Brown, G. T., Narayanan, P., Li, W., Silverstein, R. L. \& McIntyre, T. M. Lipopolysaccharide stimulates platelets through an IL-1 $\beta$ autocrine loop. J. Immunol. 191, 5196-5203 (2013)

26. Massip-Copiz, M., Clauzure, M., Valdivieso, Á. G. \& Santa-Coloma, T. A. Epiregulin (EREG) is upregulated through an IL-1 $\beta$ autocrine loop in Caco-2 epithelial cells with reduced CFTR function. J. Cell. Biochem. 119, 2911-2922 (2018).
27. Han, M. et al. Toll-like receptor 2-expressing macrophages are required and sufficient for rhinovirus-induced airway inflammation. J. Allergy Clin. Immunol. 138, 1619-1630 (2016).

28. Bentley, J. K. et al. Myristoylated rhinovirus VP4 protein activates TLR2-dependent pro-inflammatory gene expression. Am. J. Physiol. Lung Cell. Mol. Physiol. https:// doi.org/10.1152/ajplung.00365.2018. (2019).

29. Allen, I. C. et al. The NLRP3 inflammasome mediates in vivo innate immunity to influenza A virus through recognition of viral RNA. Immunity 30, 556-565 (2009).

30. Chakrabarti, A. et al. RNase $L$ activates the NLRP3 inflammasome during viral infections. Cell Host Microbe 17, 466-477 (2015).

31. Saba, T. G. et al. Rhinovirus-induced macrophage cytokine expression does not require endocytosis or replication. Am. J. Respir. Cell Mol. Biol. 50, 974-984 (2013).

32. Newcomb, D. C. et al. Human rhinovirus 1B exposure induces phosphatidylinositol 3-kinase-dependent airway inflammation in mice. Am. J. Respir. Crit. Care Med. 177, 1111-1121 (2008)

33. Wang, Q. et al. MDA5 and TLR3 initiate pro-inflammatory signaling pathways leading to rhinovirus-induced airways inflammation and hyperresponsiveness. PLoS Pathog. 7, e1002070 (2011).

34. Toussaint, M. et al. Host DNA released by NETosis promotes rhinovirus-induced type-2 allergic asthma exacerbation. Nat. Med. 23, 681-691 (2017).

35. Zhang, $\mathrm{H}$. et al. AIM2 inflammasome is critical for influenza-induced lung injury and mortality. J. Immunol. 198, 4383-4393 (2017).

36. Thomas, P. G. et al. The intracellular sensor NLRP3 mediates key innate and healing responses to influenza A virus via the regulation of caspase-1. Immunity 30, 566-575 (2009).

37. Ichinohe, T., Lee, H. K., Ogura, Y., Flavell, R. \& Iwasaki, A. Inflammasome recognition of influenza virus is essential for adaptive immune responses. J. Exp. Med. 206, 79-87 (2009)

38. Tuthill, T. J. et al. Mouse respiratory epithelial cells support efficient replication of human rhinovirus. J. Gen. Virol. 84, 2829-2836 (2003).

39. Stokes, C. A. et al. Role of interleukin-1 and MyD88-dependent signaling in rhinovirus infection. J. Virol. 85, 7912-7921 (2011).

40. Piper, S. C. et al. The role of interleukin-1 and interleukin-18 in pro-inflammatory and anti-viral responses to rhinovirus in primary bronchial epithelial cells. PLoS ONE 8, e63365 (2013).

41. Jackson, D. J. et al. Interleukin-18 is associated with protection against rhinovirus-induced colds and asthma exacerbations. Clin. Infect. Dis. 60, 1528-1531 (2015).

42. Kim, R. Y. et al. Role for NLRP3 inflammasome-mediated, IL-1 $\beta$-dependent responses in severe, steroid-resistant asthma. Am. J. Respir. Crit. Care Med. 196, 283-297 (2017).

43. Mahmutovic Persson, I. et al. IL-1 $\beta$ mediates lung neutrophilia and IL-33 expression in a mouse model of viral-induced asthma exacerbation. Respir. Res. 19, 16 (2018)

44. Menzel, M. et al. Caspase- 1 deficiency reduces eosinophilia and interleukin-33 in an asthma exacerbation model. ERJ Open Res. 3, 00047-02017 (2017).

45. Bal, S. M. et al. IL-1 $\beta$, IL-4 and IL-12 control the fate of group 2 innate lymphoid cells in human airway inflammation in the lungs. Nat. Immunol. 17, 636-645 (2016).

46. Ohne, Y. et al. IL-1 is a critical regulator of group 2 innate lymphoid cell function and plasticity. Nat. Immunol. 17, 646-655 (2016).

47. Seo, S. U. et al. Distinct commensals induce interleukin-1 $\beta$ via NLRP3 inflammasome in ilnflammatory monocytes to promote intestinal inflammation in response to injury. Immunity 42, 744-755 (2015).

48. Tsai, W. C. et al. Azithromycin blocks neutrophil recruitment in pseudomonas endobronchial infection. Am. J. Respir. Crit. Care Med. 170, 1331-1339 (2004).

49. Schneider, D. et al. Neonatal rhinovirus infection induces mucous metaplasia and airways hyperresponsiveness. J. Immunol. 188, 2894-2904 (2012).

50. Quiner, C. A. \& Jackson, W. T. Fragmentation of the Golgi apparatus provides replication membranes for human rhinovirus 1A. Virology 407, 185-195 (2010) 